\title{
Examining the Link between BECE Papers and Mathematics Curriculum Standards in Ghana
}

\author{
Awanta, E. K. \\ Department of Mathematics Education, University of Education Winneba
}

\begin{abstract}
This article seeks to explore the relationship between the implementation of the Ghanaian basic school mathematics curriculum standards and the nature of the Basic Education Certificate Examination (BECE). It covered the period between 1992 and 1999. Data for this research were collected from past BECE examination papers. The past examination papers were used to find out whether the BECE examination papers in mathematics reflected the curriculum standards. The examination papers were also used to find out whether the introduction of the mathematics curriculum standards has modified the BECE examination papers in any way. The result from the research seems to suggest that there is little evidence to prove that the BECE examination papers reflect the curriculum standards. There has not been any attempt to make any generalised claims from these finding in view of the limited period (1992-1999) this research focused on.
\end{abstract}

\section{Introduction}

A curriculum, for Howson, Keitel and Kilpatrick (1981, p.2), is clearly much more than a syllabus, and 'must encompass aims, content, methods and assessment procedures'. McCormick and James (1983) define curriculum in more pupil-centred terms as what is experienced by pupils when they are involved in learning activities and also as the outcome of learning in terms of the understandings, attitudes, etc. that pupils develop. Curriculum has also been defined as a plan for providing sets of learning opportunities for persons to be educated. Plans have no impact until they are set in motion; thus, learning opportunities remain only opportunities until learners become engaged with the opportunities. In my view, all these definitions have merit, but each is too limited. My definition incorporates everything suggested in all of them, including intentions, plans, assessment instruments, classroom teaching practices, pupil experiences and learning outcomes. The thesis of this research is concerned with relationships among different elements of the curriculum, thus broadly defined. Secondly, what should be contained in the mathematics curriculum standards?

The American National Council of Teachers of Mathematics - NCTM (1989) considers that an effective basic school mathematics programme should include dedication to improvement in the teaching of mathematics as a way of thinking and as a tool for problem solving skills. It further stated that the teaching of mathematics at elementary level must give substantial attention to concepts and skills from all strands - number, measurement, geometry, patterns and functions, statistics and probability, and logic. It asserted that these strands are not separate and unrelated mathematical topics but they are arbitrary delineations that frequently overlap. The NCTM (1989) also stated that when a set of curriculum standards are specified for school mathematics, it should be understood that the standards are value judgments. These are based on a broad, coherent vision of schooling derived from several factors such as societal goals, pupil goals, research on teaching and learning, and professional experience.

An area of concern to the researcher is that the mathematics curriculum standards that exist in Ghana, and perhaps in most countries of the world, are perhaps strongly directed towards performance techniques rather than a broader perspective such as societal goals. Arithmetical computation is entrenched as the basis of the mathematics curriculum, with the 'four rules' 
gradually being developed to handle more and more complicated 'numbers'. According to Bishop (1988), a technique curriculum is a curriculum of procedures, methods, skills, rules and algorithms which portrays mathematics as a 'doing' subject. In this case, therefore, he said it is a curriculum in which 'practice makes perfect' with examples to be emulated, and exercises to be carried out. He further contended that it involves impersonal learning, whereby the task for the learner is conceived of as being independent of the person of the learner. That is, what is considered important is that the learner learns the mathematics not that the learner strives for some personal meanings from mathematics. According to him, syllabuses, examinations, textbooks, and teacher are all dominated by the emphasis on subject knowledge and technique performance. To him the third major area of concern is characterised by 'text teaching'. In Ghanaian educational system there is one textbook and its use is mandatory. The control by the textbook might prevent teachers from knowing their learners and thereby prevent them from helping their learners. Hence in the context of Ghana, the use of textbook is crucial in curriculum development.

\section{The teacher, test and curriculum}

There is the problem as to whether teachers teach according to what is generally spelt out in the curriculum or not. The teacher's role in the classroom has been found to be very crucial in the successful implementation of policies related to curriculum development and assessment. Torrance (1988) has, for example, noted that changes in assessment and especially public examinations impact most positively on curriculum and teaching methods, when teachers have an active role in the development process. He noted:

Crude changes in curriculum content and teaching methods can be instigated, but the quality of these changes will depend on teacher perceptions of their purpose and understandings of their broader curricular intentions (Torrance, 1988:155).

Thus we cannot talk about the effective use of testing in the classroom without thinking first about how practitioners actually understand the concept of testing and how they use it in the classroom. Available literature cited by Black and William (1988) suggests that teachers do not have an in-depth understanding of what testing entails; neither do they use it well in the classroom. In a study conducted by Black (1993) for example, the following weaknesses were found to be very common in teachers' classroom testing approaches:

- classroom evaluation practices generally encourage superficial and rote learning, concentrating on recall of isolated details usually items of knowledge which pupils soon forget;

- teachers do not generally review the test questions that they use and do not discuss them critically with peers, so there is little reflection on what is being tested; and

- the grading function is over-emphasised and the learning function is under-emphasised and there is a tendency to use a normative rather than a criterion approach, which emphasises competition between pupils rather than personal improvement of each.

Other studies cited by Black and William (1988) confirm this general picture. They found that although teachers can predict the performance of their pupils on external tests, their own assessments do not tell them what they need to know about their pupils' learning. Teachers appeared to be unaware of the assessment work of colleagues and do not trust or use their assessment results. They also observed that teachers' records tend to emphasise the quantity of pupils' work rather than its quality. These situations are reflective of what pertains in the Ghana educational system. Indeed, this remark is just my opinion since there is the lack of relevant research in Ghana.

Winter (1999) reported ways in which teaching in the United States was frequently geared to examinations rather than to implementation of planned curricula. He pointed out that teachers introduced explicit test-preparation activities, using items on the tests and explained to pupils how the tests were scored and how they could do well on them. He also reported teachers giving more emphasis to certain topics (e.g. number relationships and measurement) that 
would be on the test. All these, in my opinion, appear to be a neglect of the implementation of curriculum as a whole.

\section{Perspective on implementation of curriculum}

A number of views have been expressed on the implementation of curriculum standards. Saylor, Alexander, and Lewis (1980) have defined instruction as the implementation of the curriculum plan - that is, the actual engagement of the learners with the planned learning opportunities. They contended that the curriculum planning process necessarily includes making decisions regarding instructional modes with suggestions as to resources, media, and organisation, thus encouraging flexibility and more freedom for the teacher(s) and pupils. Teachers and pupils should be free in the implementation of the curriculum plan. Thus, effective curriculum plans will not prescribe instructional procedure and materials; rather, they will describe alternative instructional models and suggest a variety of instructional materials.

Swann and Brown (1997) found that in Scotland, teachers are accustomed to working in a centralised system, and generally, there has been a relatively high level of acceptance of a non-statutory national curriculum. According to them, evidence for teacher acceptance includes research findings from the official evaluation. Aside of doubts about the value of national testing, explicit criticism of Scotland's National Curriculum seems to have focused on such issues as teacher workload, the pace of change, and questions of detail rather than on more fundamental issues of ideology and theories of learning.

Also, Swann and Brown (1997) discovered that the 5-14 programme focuses on Scotland's traditional broad curriculum areas. It is much less a syllabus than a framework of curriculum and assessment concepts, with distinctive priorities which include:

- The need to make judgments about pupils on the basis of multi-dimensional elements of performance rather than global measures

- The importance of differentiation using systematic formative assessment of individuals

- A formulation of the curriculum as objective-based with a linear model of attainment for each aspect of performance.

Teachers' thinking about their own teaching of their pupils determines what they do in classroom. Tomlinson (1989, p.157) in support of the above view articulated thus "In one form or another ... the idea of human persons as active, selective interpreters and construers is by now well-grounded and widespread in modern social science".

While this assumption may be common in the social sciences, it is often not shared by politicians, who tend to assume that the implementation of a central government initiative, such as a national curriculum, is a matter of hiring consultants to develop a body of ideas for implementation, then publishing these ideas for teachers to utilise or deliver in the classroom, with support of in-service training and coercive and/or incentive measures to encourage teacher-co-operation. Swann and Brown (1997) critically asserted that despite wide consultation and general levels of practitioner acceptance, 5-14 is still essentially a top-down initiative, and its translation from policy to practice will be subject to the difficulties apparent in the histories of similar schemes. Pratt and Silverman (1988) seem to support this assertion by Swann and Brown when they stated that:

It can also be argued that policy, quite simply cannot be translated into practice in the straightforward manner often assumed to be possible, because implementation almost inevitably leads to unexpected or unintended consequences (Swann and Brown, 1997).

If one accepts the idea that teachers' thinking is a crucial dimension in the introduction of curricula initiatives, then how to gain access to that thinking becomes an important concern. The research by Swann and Brown (1997) offers new evidence to the debate about situated cognition (Brown et al. 1989). It supports the argument that an initial emphasis on 
decontextualised formal concepts, rather than on existing activities and perceptions of the learner, is unlikely to lead to learning or, in this case, the successful implementation of a national curriculum. This argument has profound implications not only for the idea of delivering curriculum content to children, but also for the ways in which National Curricula are devised and developed for use by teachers. A perspective (e.g. Berman, 1986) - offered as part of a critique of power perspective (power perspective according to Firestone et al. is a situation where actors at each level as relatively independent agents with their own interests, possess resources that can be used to influence or deflect the persuasive efforts of others) - suggests that the real challenge of local implementation is learning. According to him, central policies often ask people at lower levels to do things they do not know how to do, and aggressive punishment will not facilitate the implementation of changes that people do not understand. In fact, according to Cohen and Barnes (1993, p.207),

Policy makers ... are often blissfully ignorant of the learning that their creations entail for enactors. But policies and programmes regularly propose novel purposes. If they did not, they would be completely redundant. Some learning is required to achieve any new purpose.

Apart from the prospects of successful implementation of curriculum standards, research studies indicate that there are obstacles in the process. One of such studies is Johnson (1996). $\mathrm{He}$ categorically maintained that difficulties are encountered in the implementation of selected topics in mathematics - effectiveness of in-school planning, consideration of the nature of whole-school/department and individual teacher planning and associated review procedures, especially the extent to which teachers were basing these on $\mathrm{NC}$ documents. One other diagnosis of implementation failure was that central governments lacked sufficient power - in the form of desired resources or effective constraints - to shape local responses (e.g., Cohen and Spillane, 1993). The practical response to this diagnosis has been to introduce policies that increase centrally deployable sanctions. Academic critiques have usually emphasised the probable or actual negative unintended consequences of such deployment of sanctions (Corbert and Wilson, 1991; Murnane and Cohen, 1986). According to them, the English-Welsh version of this is the legislatively prescribed National Curriculum and associated testing procedures, which, for the first time, provided policy levers for the central government to directly influence curriculum content in schools.

This review has clarified the concept of curriculum, and explored views that people hold about the influence of curriculum change on classroom practices, in terms of teaching and learning of mathematics. It emerged very clearly that official statements of curriculum standards, however clear and admirable they might be, are unlikely to be translated into classroom teaching and learning practice unless many supportive conditions are in place. Furthermore, it also emerged that teachers and pupils tend, in response to the importance placed on examination results by the public, to shape their classroom practice more in response to the examination questions they anticipate than in response to official curriculum standards.

\section{Methodology}

\section{General methods for answering the research questions}

In order to establish the link between BECE papers and the curriculum standards the researcher analysed some past BECE examination papers. The choice of the examination papers enabled him to explore how far the questions reflected the curriculum standards, as well as to explore any changes in terms of content and structure since the introduction of the curriculum standards. I was convinced by Firestone et al. (Winter, 1999, p.779) who illuminated ways in which teaching is frequently geared to examinations rather to implementation of planned curricula. They discovered that teachers introduce explicit testpreparation activities, using items on the tests and explaining to pupils how the tests are scored and how to do well on them, and that teachers reported giving more emphasis to certain topics (e.g. number relationships and measurement) that would be on the test. 


\section{Analysis of the Examination Questions}

In any official or national system that is supposed to be used publicly (e. g. the BECE of Ghana), there is an obvious concern about how well the system operates: Does it work well? It is of course a personal judgment as to how well is well enough. In the case of this research, the analysis of the examination questions provided information for the establishment of the link between BECE papers and the curriculum standards.

\section{The 1992 Paper}

In this paper the first question asked the pupils to solve an algebraic expression of the form $5 x-3(x-1) \geq 39$. This question seems to test the manipulative skills of the pupils, since the major task of solving this problem is the ability to remove the brackets and rearrange like and unlike terms, taking account of the inequality sign. The same question also asked pupils to make ' $t$ ' the subject of the relation $V=U+t$. The approach to solving this equation is not quite different from that of the earlier part of the question. This question does not seem to be related to any of the five curriculum goals, the pupils would only have to execute the procedures of re-arrangement.

The second question provides pupils with information about percentages of income tax and property tax that can be deducted from workers salary. They were asked to find the percentage of a given amount. This question tasked the pupils to apply problem-solving skills. It was also to encourage real-world applications. Thus, it was likely to fall under the category of making meaningful mathematical connections.

Question 3 was on geometry and transformation. The pupils were asked to plot given points on the $x-y$ co-ordinate plane and find the images of these points by reflecting them. This question required the application of the concept of reflection. The task involved yielded information about the extent to which the pupils have integrated their knowledge of geometric concepts, hence this question was likely to be the type that required application of concepts of space and measures.

The fourth question showed the distribution of the masses of pupils in a school. The pupils were asked to draw a bar chart for the distribution. This question explored the experiences of the pupils in collecting, organising, displaying, and interpreting data as well as making decisions. Thus the question encouraged the use of practical activities and of making meaningful mathematical connections in relation to handling data.

The final question was on the construction of a triangle with the use of a pair of compasses and a ruler only. Even though the question appeared to be requiring purely routine procedures, the geometric descriptions given were not related to real and practical objects. One would have expected references to be made from pupils' locality like 'the corner of a bedroom', 'the corner of a tuning fork' (triangle) and so on.

\section{The 1999 Paper}

The 1999 BECE is a recent paper set after the introduction of the new standards. With its 'modern' nature, one would expect its items to immensely reflect the aspirations and goals of the standard document. What is it then?

Question 1 was in two parts. The first part mentions two boys who have been given an amount of money to share. One had a specified amount more than the other. The pupils were asked to find each of the boys' share. The second part was much like the first. It was stated that "A trader paid $\phi 1,500.00$ for 6 drinking cups. One of the cups got broken. He sold the remaining 5, making a profit of $10 \% ”$. ( $\varnothing$ is the symbol for Ghana currency, called the cedi). The pupils were expected to calculate the:

cost price of each of the six cups 
(ii) selling price of the five cups and

(iii) profit made on each cup.

Apart from it requiring the routine procedures of calculating selling and cost price as well as percentages, this question required the pupils to apply the concepts of addition and subtraction. The pupils were expected to also make an understanding and develop logical reasoning about the situation. The use of practical activities and the development of problem-solving skills have been incorporated in this question - the buying, selling and sharing with familiar currency with known objects testify.

Question 2, which had been subdivided into three parts and was completely different from Question 1. The first part asked the pupils to solve a given inequality, the second part tasked them to find the value of the expression $2 x-3 y$, given $x=\frac{1}{4}$ and $y=-\frac{1}{2}$.

The third part gave statistics of pupils in a class who took an examination in mathematics and science. It gave the breakdown of passes and non-passes and asked pupils to find how many passed in mathematics and the probability of meeting a student who passed in one subject. The first and second parts of this question seemed to examine pupils' routine procedures in dealing with inequalities as well as the techniques of substituting variables to obtain a value, and all these in my opinion involve, perhaps, mainly arithmetic computation or the execution of an algorithm and could be judged as not fitting any of the five curricula goals listed at the beginning of this analysis section. In support of this, Firestone, et al. $(1999$, p.782) argued that problems like fractions to reduce or polynomials to factor are designed to help pupils master an operation or procedure. They maintained that these never provided opportunities for analytical reasoning. However, in the third part, attempt has been made to incorporate some real-world problem and hence assessing pupils' use of practical activities and problem-solving skills.

Question 3 is purely geometry. The first part of the question demanded the pupils to construct a named triangle and also to construct a perpendicular from one vertex to meet one line. The second part asked pupils to calculate the area of the triangle constructed. This question looks almost like the fifth question of the 1992 paper. However, more mathematical thinking is involved in this paper. The pupils were to recall the procedures of constructing a perpendicular as well as the ideas/concepts of area of a triangle and apply some manipulative skills to calculate the area. Apart from the question requiring purely routine procedures, it also requires the pupils to apply some concepts.

Like question 3 of the 1992 paper, the fourth question of this paper was also on geometry. However, this question excluded 'transformation' and rather demanded pupils to do practical measurements of two given angles using a protractor. One other interesting feature of this question is that pupils were tasked to identify an angle name (e.g. alternate, vertically opposite, corresponding etc.) common to two given angles and also to state a relationship (e.g. parallel, perpendicular, etc) between two given lines. This aspect, I think really tested the extent to which the pupils have grasped of basic geometric concepts. This question is concerned with shape and space and measure, but apart from limited practical activities does not seem to relate directly to any of the suggested curriculum goals.

The last question, which was on handling data, is presented in Box 1. 
The table below shows the marks scored out of 10 by some candidates in a test.

\begin{tabular}{|l|l|l|l|l|l|l|l|l|}
\hline Marks & 1 & 2 & 3 & 4 & 5 & 6 & 7 & 8 \\
\hline No. of Candidates & 2 & 3 & 5 & 7 & 8 & 13 & 7 & 5 \\
\hline
\end{tabular}

(a) From the table above, find

(i) the modal mark

(ii) how many candidates took the test

(iii) the mean mark

(b) If $20 \%$ of the candidates failed,

(i) how many failed?

(ii) what is the least mark a candidate should score in order to pass?

Box 1

This question had a lot to offer as far as the standard themes are concerned. One needed to understand what a mode is before one could find the modal mark. Interestingly enough, some pupils defined the mode as the highest frequency, instead of the mark or score with the highest frequency. If the former definition is taken then one should not be surprised to see pupils writing 13 instead of 6 as the answer. This item therefore required both critical classification and application of concept. The pupils were also tasked to make explicit connection and understanding of multiplication as successive addition. The pupils were to perform pair-wise multiplication (i.e. frequency times the mark - $f x$ ) and then sum them up ( $\left.\sum f x\right)$ before they can tell how many candidates took the test. Generally, the question has presented a practical scenario (candidates' scores). It also required the use of problem-solving skills (if $20 \%$ of the candidates failed, how many failed?) and the use of logical reasoning (what is the least mark a candidate should score in order to pass?).

\section{Discussions}

\section{Have the Curricula goals been met?}

Having analysed the above two papers of different eras, it is critical to reflect on the following questions:

- Has the use of practical activities been encouraged?

- Have problem-solving skills been developed?

- Has room been created to facilitate discussion of mathematical ideas?

- Have both the development of logical reasoning and the meaningful making of mathematical connections been encouraged?

Critical examination of the 1992 and 1999 papers reveals that there has not been any significant increase in encouragement of the use of practical activities, development of problem-solving skills, the facilitation of discussion of mathematical ideas and the development of logical reasoning and the making of meaningful mathematical connections. 
The wording and structure, as well as the content of the test items are almost identical, suggesting that nothing new has occurred. Furthermore, in the 1999 paper, relatively few items could be judged to be related to one or two of the current standards. But those that are judged to be related required the implicit or explicit performance of activities such as drawing a figure or reading results from statistical data.

Basic skills of calculation were tested, but a lot of times in isolation from applications of real problems. Some of the 'modern' contents were tested through questions, that appeared not to be properly focused (consider the first and second parts of question 2 of the 1999 paper for instance). On the whole, estimation, approximation, limits of accuracy and significant figures found a place on the standard documents, but were only occasionally examined. There were varieties of questions during the period under review. Indeed, this should have meant that a wider range of content of the Standard document could be tested. The move throughout this period, however, seemed to have been, if anything, away from practical, activity-based assessments. There are question marks about the authenticity of these tests, since they do not suggest constituting an appropriate representation of the range of mathematical performance required by the curriculum. There was no clearly detectable difference between these two tests in their coverage of the new curriculum, although there is some evidence that both these tests give a better coverage of the range of content of the curriculum than did those in the years before 1990 .

Looking at the nature of the questions, it is suggestive that there were problems in assessing shape, space and measures. This, perhaps, is because of the lack of practical handling of shapes. Even in the other aspects of the curriculum, there seem to have been problems devising simple questions that allowed the assessment of aspects of the mathematics curriculum such as: recognising relationships, developing individualistic mental methods and solving problems through understanding and relating mathematics to purposeful contexts.

By their nature, the objective tests did not measure descriptive ability or powers of selfexpression nor did it require interpretation of the answers. The quality of the written tests varied. Many of the test items used do not appear to be good as indicators of levels of National Curriculum achievement. Most of the questions tested simple recall of information and gave insufficient weight to understanding. For example, question 3 of section $\mathrm{B}$ of the 1999 paper asked pupils to use a pair of compasses and a ruler only to construct a triangle $\mathrm{ABC}$ with the various dimensions given. The same question required the pupils to calculate the area of the triangle they had constructed. Here, pupils were rarely asked to justify their answers. Test items were designed away from real-world applications and there are no prompts to give written justifications for solutions.

Assessment of the skills of mathematical investigations was weak. The tests have retained the same format over the years (including the years before the new curriculum reforms). The assessments do not cover the process achievable target, 'Using and Applying'.

Surprisingly, the use of calculators in the tests has been prohibited. The researcher is not sure how much longer this situation will continue. It should be emphasised that for some parts of the tests a calculator cannot be used for some questions, say in geometric drawing or coordinates. However, some of the questions in the examination papers can be tackled much more efficiently and rapidly with the support of a calculator. In any case, the exclusion of the use of the calculator does not have any significant influence on the pupils' tasks performance since almost all the questions tackled were fairly straightforward to be answered in the time available.

\section{Limitation}

The study drew upon very few past examination papers, and moreover, only two past papers, one each for the 'old' and 'new' systems were compared and contrasted. The scope therefore, is very limited for any generalisations to be established, hence there is the need for a further and more detailed study into this problem. 


\section{References}

Berman, P. E. (1986). From compliance to learning: Implementing legally-induced reform. In D. Kirp and D. Jensen (Eds.), School days, rule days (pp. 46-62). Philadelphia: Falmer Press.

Black, P. and William (1988). 'Inside The Black Box'. Raising Standards Through Classroom Assessment: London.

Black, T. R. (1993b.). Evaluating Social Science Research. An Introduction. London: Sage.

Brown, J. S., Collins, A. and Duguid, P. (1989). Situated Cognition and the Culture of Learning, Educational Researcher, 18, 1, 32-42.

Cohen, D. K., and Barnes, C. A. (1993). Pedagogy and policy. In D. K. Cohen, M. W. McLaughlin, and J. E. Talbert (Eds.), Teaching for understanding (pp. 207-239). San Francisco: Jossey-Bass.

Cohen, D. K., and Spillane, J. P. (1993). Policy and practice: The relations between Governance and instruction. In S. H. Fuhrman (Ed.), Designing coherent education policy (pp. 35-95). San Francisco: Jossey-Bass.

Corbert, H. D., and Wilson, B. L. (1991). Testing, reform, and rebellion. Norwood, NJ: Ablex.

Howson, A. G., Keitel, C. and Kilpatrick, J. (1981). Curriculum Development in Mathematics. Cambridge University Press.

Johnson, D. C. and Millett, A. (1996). Implementing the mathematics national Curriculum: policy, politics and practice. London: Paul Chapman.

McCormick, R. and James, M. (1983). Curriculum Evaluation in Schools. $2^{\text {nd }}$ edition. Croom Helm Ltd.

Murnane, R. J. and Cohen, D. K. (1986). Merit pay and the evaluation problem: Why some merit pay plans fail and a few survive. Harvard Educational Review. 56, 1-17.

National Council of Teachers of Mathematics (March, 1989). Curriculum Standards for Grades 5-8. Curriculum and Evaluation Standards for School Mathematics, pp. 112115. NCTM: United States of America.

Pratt, J. and Silverman, S. (1998). Responding to Constraint: Policy and Management in Higher Education. Buckingham: Open University Press.

Saylor, J. G., Alexander, W. M., and Lewis, A. J. (1980). Curriculum Planning for Better Teaching and Learning. Canada: Holt, Rinehart and Winston.

Scottish Office Education Department (1994). Implementing 5-14; Progress Report (Interchange No. 23, February) Edinburgh: SOED.

Swann, J. and Brown, S. (1997). The Implementation of a national curriculum and teachers' classroom thinking. Research Papers in Education. 12(1) pp. 91-114.

Tomlinson, P. (1989). 'Having it both ways: hierarchical focusing as research Interview method', British Educational Research Journal, 15, 2, 155-76.

Torrance, H. (1988, ed.). National Assessment and Testing: A Research Response. London: British Educational Association.

Winter, (1999). Power, Learning, and Legitimation: Assessment Implementation across Levels in the United States and the United Kingdom. American Educational Research Journal: v36n4 pp. 759-793.

Woods, P., Bagley, C., and Glatter, R. (1998). School choice and competition: Markets in the public interest? London: Routledge. 